\title{
Polymorphisms of the matrix metalloproteinases associated with prostate cancer
}

\author{
SABRINA THALITA DOS REIS ${ }^{1}$, FABIOLA ELIZABETH VILLANOVA ${ }^{1}$, PRISCILA MARIA DE ANDRADE ${ }^{1}$, \\ JOSÉ PONTES Jr ${ }^{1}$, IRAN AMORIM SILVA ${ }^{1}$, FLÁVIO CANELAS CANAVEZ ${ }^{2}$, ADRIANA SAÑUDO ${ }^{1}$, \\ MIGUEL SROUGI $^{1}$ and KÁTIA RAMOS MOREIRA LEITE ${ }^{1}$ \\ ${ }^{1}$ Laboratory of Medical Investigation (LIM55), Urology Department, Faculdade de Medicina da \\ Universidade de São Paulo (FMUSP); ${ }^{2}$ Genoa Biotechnology, São Paulo, SP, Brazil
}

Received January 17, 2008; Accepted March 24, 2008

\begin{abstract}
Prostate cancer (PCa) is the most common type of malignant tumor in Brazilian males. Single nucleotide polymorphisms (SNPs) have been demonstrated to be present in the promoter region of matrix metalloproteinase (MMP) genes and have been associated with the development and progression of some cancers. In this study, our aim was to investigate the association between the polymorphisms of MMP1, 2, 7, and 9 and susceptibility, and their correlation with the classic prognostic parameters of PCa. For genes MMP1, 2 and 9, the frequencies of the polymorphic homozygote genotypes were higher in the control group than in the PCa group $(\mathrm{P}<0.0001)$. We conclude that the MMP1, 2 and 9 polymorphisms are more common in the control group than in patients with $\mathrm{PCa}$, and may have a protective effect in the development of this neoplasia.
\end{abstract}

\section{Introduction}

Prostate cancer (PCa) is a disease with a multifactorial and complex etiology. It is the most common male malignancy and the second leading cause of death in many countries, including Brazil (1). The worldwide incidence of PCa varies widely among different ethnic groups and geographical areas (2). The widespread use of prostate-specific antigen and digital rectal examination in the diagnosis of this cancer has increased

Correspondence to: Dr Sabrina Thalita dos Reis, Fundação Faculdade de Medicina da Universidade de São Paulo, Av. Dr. Arnaldo $455,2^{\circ}$ andar, sala 2141, Cerqueira César, São Paulo, SP, Brazil

E-mail: sasareis@gmail.com

Abbreviations: MMP, matrix metalloproteinase; PCR, polymerase chain reaction; PCa, prostate cancer; SNP, single nucleotide polymorphism

Key words: disease susceptibility, metalloproteinases, polymorphism, prognosis, prostate cancer its detection at earlier stages; however, these diagnostic methods have proven insufficient for the identification of the disease (3). Research has therefore been focused on the identification of molecular markers that can predict a predisposition to PCa.

Matrix metalloproteinases (MMPs) are an important family of metal-dependent enzymes responsible for the degradation of extracellular matrix components, including the basement membrane, interstitial collagen, fibronectin and the various proteoglycans involved in physiologic processes such as embryogenesis and tissue remodeling $(4,5)$. They also play a key role in the invasion of tumor cells and in metastasis, which require the proteolysis of the basal membranes and the extracellular matrix (6). Previously, MMPs were considered to be almost exclusively involved in these two steps of carcinogenesis. However, it was recently suggested that MMPs are involved in several other processes associated with cancer development. Indeed, they have proven to regulate tumor growth and apoptosis, promote angiogenesis and induce the loss of cell adhesion, facilitating invasion and metastasis. Some are also required in immune responses to cancer (7). Although the overexpression of MMPs is found in many tumor tissues, somatic cell mutation and the gene transposal of MMPs are rarely observed. Genetic variants that influence the level of MMP gene expression or protein function could therefore be expected to influence the role these enzymes play in tumor invasion and metastasis (8).

A functional single nucleotide polymorphism (SNP) has been reported in the MMP1 gene promoter consisting of a guanosine $(\mathrm{G})$ insertion at position -1607 . This SNP generates a new 5'-GGA-3' core recognition sequence for members of the Ets family of transcription factors; the $2 \mathrm{G} / 2 \mathrm{G}$ genotype was reported to be linked to an increased risk of colorectal cancer (9). A common functional polymorphism that abolishes an Sp1-binding site has been described for the promoter region of MMP2 (-1306 C/T) (10), and the TT genotypes have been associated with a reduced risk of lung (11), gastric (12) and breast (13) cancer. In the MMP7 gene promoter region, one SNP (-181A/G) has been shown to modify gene transcription activity and is associated with increased susceptibility to esophageal squamous cell carcinoma, gastric cardiac adenocarcinoma and non-small cell lung carcinoma (14). In the MMP9 gene, a functional SNP (R279Q) that presumably 
Table I. Primers used in the genotyping of SNPs in the MMP genes.

Gene/SNP

MMP1-1607 1G/2G

MMP2-1306 C/T

MMP7-181 A/G

MMP9-R279Q
Primers 5'-3'

TGACTTTTAAAACATAGTCTATGTTCATCTTGGATTGATTTGAGATAAGTCATAGC

CTGACCCCCAGTCCTATCTGCCTGTTGGGAACGCCTGACTTCAG

TGGTACCATAATGTCCTGAATGTCGTTATTGGCAGGAAGCACACAATGAATT

GAGAGATGGGATGAACTGGTGGTGGAAATGTGGTGT enhances substrate binding $(15,16)$ potentially alters the protein structure of MMP9 and may have some functional relevance, affecting an individual's susceptibility to cancer (17).

The aim of this study was to explore whether the MMP1,2, 7 and 9 gene polymorphisms are involved in the risk of $\mathrm{PCa}$ occurrence.

\section{Materials and methods}

Patients. A case-control study was conducted using surgical specimens from 100 patients aged $65 \pm 6.9$ years $($ mean \pm SD) who underwent a radical prostatectomy between 1993 and 2007 at the Department of Urology, Hospital das Clínicas da Universidade de São Paulo and Hospital Sírio Libanês de São Paulo. The prostate samples were formalin-fixed, paraffinembedded and examined in toto by one uropathologist (KRML). To avoid the identification of mutations due to neoplasia, the samples were representative of normal tissue, mostly vesical margin negative for tumor.

A total of 100 serum samples from healthy men (aged $54 \pm 7.4$ years) were used as controls. Their prostate-specific antigen levels were within normal limits $(<2.5 \mathrm{ng} / \mathrm{ml})$ and digital rectal examinations of the prostate showed no abnormalities.

Both groups were representative of the ethnic diversity of all regions of Brazil, as both hospitals are designated treatment centers for urological cancer.

All subjects in both groups provided informed consent for their participation in the study and for their biological samples to be genetically analyzed. The study was approved by the Institutional Board of Ethics (no. 769/06).

Analysis of SNPs in the MMP genes. Genomic DNA was extracted from paraffin blocks and serum using conventional protocol [Wright and Manos (18)] and the GFX Kit (GE Healthcare, UK), respectively. The SNPs were genotyped using the TaqMan ${ }^{\circledR}$ SNP Genotyping Assay Kit and an ABI 7500 Fast System (Applied Biosystems, CA, USA).

SNP-specific polymerase chain reaction (PCR) primers (Table I) and fluorogenic probes were designed using Primer Express (Applied Biosystems). These fluorogenic probes are labeled with a reporter dye $\left(\mathrm{FAM}^{\mathrm{TM}}\right.$ or $\left.\mathrm{VIC}^{\circledR}\right)$ and are specific for one of the two possible bases identified at the four SNPs in the MMPs.

The target sequence was amplified in a $10-\mu 1$ reaction volume containing $5 \mu 1$ TaqMan ${ }^{\circledR}$ Universal PCR Master Mix, $0.25 \mu \mathrm{l}$ SNP Genotyping Assay (primers and probes), $1 \mu 1$

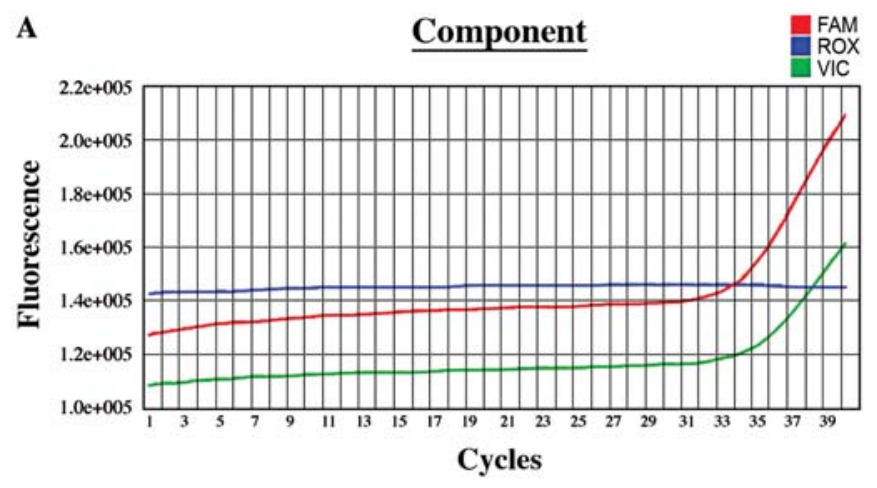

B

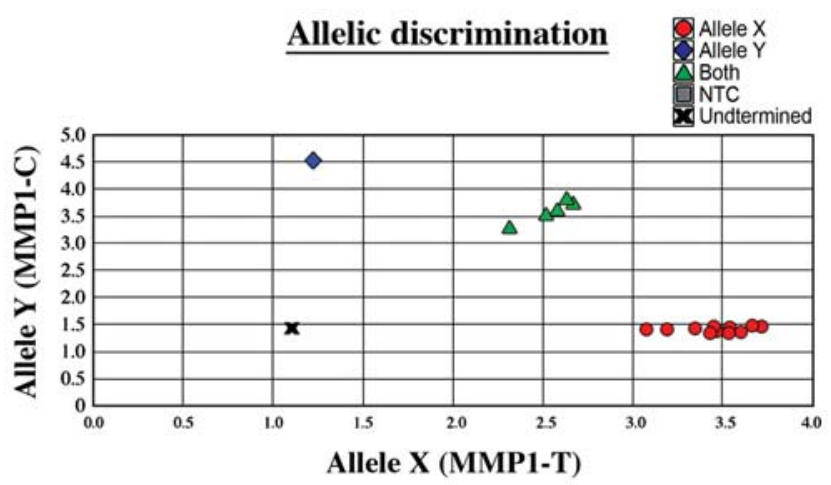

Figure 1. (A) Results of genotyping. The blue and red curves represent the amplification signal of both fluorescent VIC and FAM reporter dyes, in accordance with the number of PCR cycles, characterizing the one heterozygote genotype. (B) Results of the MMP real-time PCR reaction of all the patient and control genotypes in one plate. Red dots represent homozygotes for allele 1, green triangles heterozygotes, and blue lozenges homozygotes for allele 2 .

genomic DNA and 3.75 $\mu 1$ DNase-free water. The PCR cycling conditions were $2 \mathrm{~min}$ at $50^{\circ} \mathrm{C}$ and $10 \mathrm{~min}$ at $95^{\circ} \mathrm{C}$, followed by 40 cycles of $15 \mathrm{sec}$ at $95^{\circ} \mathrm{C}$ and $60 \mathrm{sec}$ at $60^{\circ} \mathrm{C}$. After PCR amplification, an endpoint plate reading was performed using the Applied Biosystem Real-Time PCR 7500 Fast System. The fluorescence measurements made during the plate reading were used by Sequence Detection System Software to plot fluorescence $(\mathrm{Rn})$ values based on the signals from each well. These plotted fluorescence signals indicate which alleles were in each sample (Fig. 1).

Statistical analysis. The genotype and allele frequencies in the PCa and control groups were compared using $\chi^{2}$ analysis. Differences in pathological stage and Gleason score were also compared. $\mathrm{P}<0.05$ was required for statistical significance. 


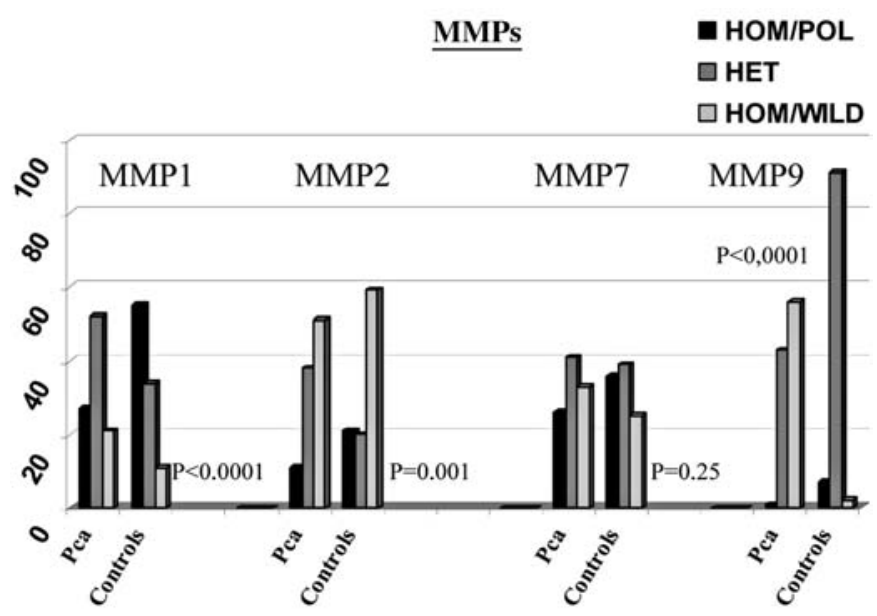

Figure 2. Genotype distribution of the MMP genes between the PCa patients and healthy controls. The Y-axis represents the number of genotypes of the MMP polymorphisms of the patients and controls. HOM/POL, homozygote polymorphic; HET, heterozygote; HOM/WILD, homozygote wild-type.

\section{Results}

The genotypic distributions between PCa patients and controls are shown in Fig. 2. They did not deviate significantly from the expected values of the Hardy-Weinberg equilibrium.

We found statistically significant differences between patients and controls in the distribution of genotypes in the MMP1, 2 and 9 genes. In the MMP1 gene, the frequencies of the $1 \mathrm{G} / 1 \mathrm{G}, 1 \mathrm{G} / 2 \mathrm{G}$ and $2 \mathrm{G} / 2 \mathrm{G}$ genotypes were 55,34 and $11 \%$ respectively in healthy controls, and 27,52 and $21 \%$ respectively in $\mathrm{PCa}$ patients $(\mathrm{P}=0.0001)$. In the MMP2 gene, the frequencies of the CC, CT and TT genotypes were 21, 20 and $59 \%$ respectively in healthy controls, and 11, 38 and $51 \%$ respectively in $\mathrm{PCa}$ patients $(\mathrm{P}=0.01)$. In the MMP9 gene, the frequencies of the $\mathrm{AA}, \mathrm{AG}$, and $\mathrm{GG}$ genotypes were 7, 91 and $2 \%$ respectively in healthy controls, and 1, 43 and $56 \%$ respectively in PCa patients $(\mathrm{P}=0.0001)$. In the MMP7 gene, the frequencies of the AA, AG, and GG genotypes were 25, 39 and $36 \%$ respectively in healthy controls, and 33,41 and $26 \%$ respectively in $\mathrm{PCa}$ patients $(\mathrm{P}=0.25)$ (Fig. 2).

Statistical differences were also found between $\mathrm{PCa}$ patients and controls in terms of allelic frequencies. In MMP1, the $1 \mathrm{G}$ and $2 \mathrm{G}$ alleles were detected in 72 and $28 \%$ of the healthy controls, respectively, and in 53 and $47 \%$ of the $\mathrm{PCa}$ patients, respectively $(\mathrm{P}=0.0001)$. In MMP9, the $\mathrm{A}$ and $\mathrm{G}$ alleles were detected in 52 and $48 \%$ of healthy controls, respectively, and in 22 and $88 \%$ of PCa patients, respectively $(\mathrm{P}=0.0001)$. In the MMP2 and 7 genes, the differences did not reach statistical significance. In MMP2, the $\mathrm{T}$ and $\mathrm{C}$ alleles were present in 31 and $69 \%$ of healthy controls, respectively, and in 30 and $70 \%$ of $\mathrm{PCa}$ patients, respectively $(\mathrm{P}=0.80)$. In MMP7, the A and $\mathrm{G}$ alleles were detected in 44 and $56 \%$ of healthy controls, respectively, and in 53 and $47 \%$ of $\mathrm{PCa}$ patients, respectively ( $\mathrm{P}=0.07$ ) (Fig. 3).

\section{Discussion}

In this case-control study, we investigated the association of SNPs in the MMP1, 2, 7 and 9 genes with predisposition to

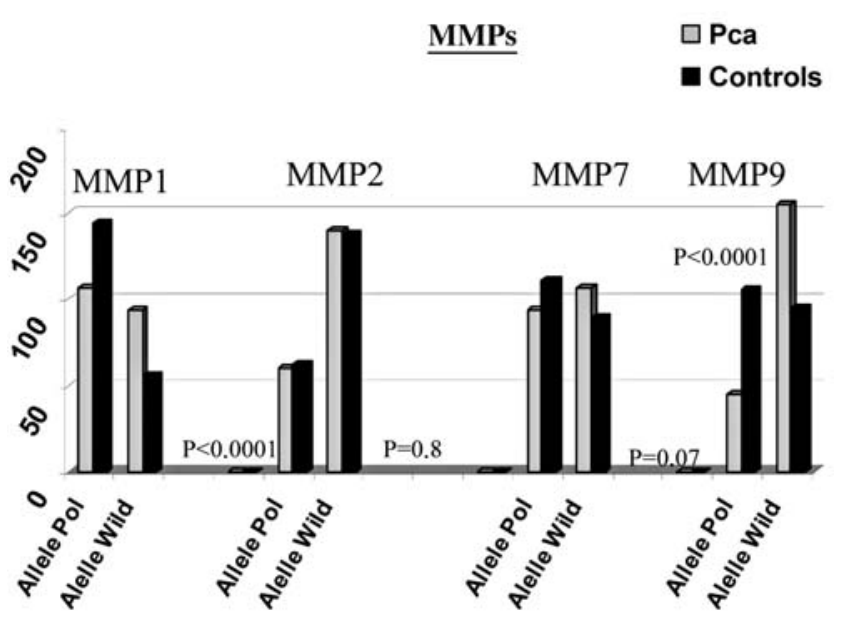

Figure 3. Comparison of the allelic frequencies of the MMP genes in the PCa patients and the controls. The Y-axis represents the number of alleles of the MMP polymorphisms in the PCa patients and the controls. Allele Pol, allele polymorphic; Allele Wild, allele wild-type.

PCa and with PCa stage and Gleason score. The 2G/2G, TT and AA polymorphic genotypes in the MMP1, 2 and 9 genes were significantly more prevalent in controls, suggesting that polymorphisms may play a role in protecting our population against the development of PCa. Most likely, these polymorphisms confer lowered promoter activity in the MMP1, 2 and 9 genes, which may be associated with a decreased risk of developing PCa. In other studies, the MMP2 -1306 C/T polymorphism has been associated with a reduced risk of lung (11), gastric (12) and breast (13) cancer.

On the other hand, an association between MMP polymorphisms and the risk of developing neoplasias has been demonstrated. Zhang et al (14) showed the $-181 \mathrm{~A} / \mathrm{G}$ polymorphism in the MMP7 promoter to be associated with the risk of developing esophageal squamous cell carcinoma, gastric cardiac adenocarcinoma and non-small cell lung carcinoma.

Other researchers have not demonstrated an association between MMP polymorphisms and the risk of or protection against the development of tumors. Lai et al (23) found no association between the $-16071 \mathrm{G} / 2 \mathrm{G}$ polymorphism in the MMP1 gene and the risk of head and neck carcinoma. Hu et al (17) demonstrated that the R279Q polymorphism in the MMP9 gene did not influence the development of lung cancer. $\mathrm{Xu}$ et al (24) showed no association between the $1306 \mathrm{C} / \mathrm{T}$ polymorphism in the MMP2 gene and the risk of colorectal carcinoma.

MMPs are zinc metalloproteases that degrade the collagens of the extracellular matrix important in tissue remodeling and repair during development and inflammation. MMPs may alter cell cycle checkpoint controls, may conceivably promote genomic instability by affecting cell adhesion (19) and contribute to tumor initiation and development by altering the cellular microenvironment responsible for facilitating tumor formation (20). A role for MMPs in angiogenesis has also been advocated (21).

Excessive or inappropriate expression of MMPs may contribute to the pathogenesis of cancer in a wide variety of diseases by facilitating the degradation of tissues. Currently, more than 20 MMPs that can be categorized by substrate specificity 
have been identified. Functional polymorphisms associated with characteristics of the expression of these genes may be used as genetic biomarkers in the diagnosis and prognosis of neoplasias (22).

Regarding PCa specifically, only one study by Sfar et al (25) has been conducted. The study investigated the impact of the $-1562 \mathrm{C} / \mathrm{T}$ polymorphism on the MMP9 gene, suggesting that the polymorphism is an independent risk factor for $\mathrm{PCa}$ development and progression in a population from Tunisia. The characteristics and the number of patients in that study were similar to those of the present study, but the polymorphism was different.

The analysis of genetic polymorphisms in a Brazilian population is interesting as the country has a 500-year history of interethnic mixing between Europeans, Africans and Amerindians. It has previously been shown that there is no correlation between race and ancestry in Brazil, which makes it difficult to classify the distribution of SNPs and ethnicity (26). However, Ju et al (27), studying the MMP1 1607 1G/2G polymorphism, showed a similar frequency of the polymorphism among Brazilians, Europeans and Americans, which suggests that the racial diversity of Brazilians should not interfere with the interpretation of our results.

In conclusion, we have demonstrated an association between the $-16071 \mathrm{G} / 2 \mathrm{G},-1306 \mathrm{C} / \mathrm{T}$ and R279Q polymorphisms of the MMP1, MMP2 and MMP9 genes with protection against the development of PCa.

\section{References}

1. Jemal A, Siegel R, Ward E, Murray T, Xu J and Thun MJ: Cancer Statistics, 2007. CA Cancer J Clin 57: 43-66, 2007.

2. Jemal A, Siegel R, Ward E, Murray T, Xu J, Smigal C and Thun MJ: Cancer Statistics, 2006. CA Cancer J Clin 56: 106-130, 2006.

3. Partin AW, Kattan MW, Subong EN, et al: Combination of prostate-specific antigen, clinical stage, and Gleason score to predict pathological stage of localized prostate cancer. A multiinstitutional update. JAMA 277: 1445-1451, 1997.

4. Nelson AR, Fingleton B, Rothenberg ML and Matrisian LM: Matrix metalloproteinases: biologic activity and clinical implications. J Clin Oncol 18: 1135-1149, 2000.

5. Visse R and Nagase H: Matrix metalloproteinases and tissue inhibitors of metalloproteinases: structure, function, and biochemistry. Circ Res 92: 827-839, 2003.

6. Forget MA, Desrosiers RR and Beliveau R: Physiological roles of matrix metalloproteinases: implications for tumor growth and metastasis. Can J Physiol Pharmacol 77: 465-480, 1999.

7. Egeblad M and Werb Z: New functions for the matrix metalloproteinases in cancer progression. Nat Rev Cancer 2: 161-174, 2002.

8. Curran S and Murray GI: Matrix metalloproteinases in tumor invasion and metastasis. J Pathol 189: 300-308, 1999.

9. Zinzindohoue F, Lecomte T, Ferraz JM, Houllier AM, Cugnene PH, Berger A, Blons H and Laurent-Puig P: Prognostic significance of MMP-1 and MMP-3 functional promoter polymorphisms in colorectal cancer. Cin Cancer Res 15: 594-599, 2005.

10. Price SJ, Greaves DR and Watkins H: Identification of novel, functional genetic variants in the human matrix metallo-proteinase-2 gene: role of SP-1 in allele-specific transcriptional regulation. J Biol Chem 276: 7549-7558, 2001.
11. Yu C, Pan K, Xing D, Liang G, Tan W, Zhang L and Lin D: Correlation between a single nucleotide polymorphism in the matrix metalloproteinase-2 promoter and risk of lung cancer. Cancer Res 62: 6430-6433, 2002.

12. Miao X, Yu C, Tan W, Xiong P, Liang G, Lu W and Lin D: A functional polymorphism in the matrix metalloproteinase-2 gene promoter $(-1306 \mathrm{C} / \mathrm{T})$ is associated with risk of development but not metastasis of gastric cardiac adenocarcinoma. Cancer Res 63: 3987-3990, 2003.

13. Zhou Y, Yu C, Miao X, Tan W, Liang G, Xiong P, Sun T and Lin D: Substantial reduction in risk of breast cancer associated with genetic polymorphisms in the promoters of the matrix metalloproteinase-2 and tissue inhibitor of metalloproteinase- 2 genes. Carcinogenesis 25: 399-404, 2004.

14. Zhang J, Jin X, Fang S, Wang R, Li Y, Wang N, Guo W, Wang Y, Wen D, Wei L, Dong Z and Kuang G: The functional polymorphism in the matrix metalloproteinase-7 promoter increases susceptibility to esophageal squamous cell carcinoma, gastric cardiac adenocarcinoma and non-small cell lung carcinoma. Carcinogenesis 26: 1748-1753, 2005.

15. Allan JA, Docherty AJ, Barker PJ, Huskisson NS, Reynolds JJ and Murphy G: Binding of gelatinases A and B to type-I collagen and other matrix components. Biochem J 309: 299-306, 1995.

16. O'Farrell TJ and Pourmotabbed T: Identification of structural elements important for matrix metalloproteinase type $\mathrm{V}$ collagenolytic activity as revealed by chimeric enzymes. Role of fibronectin-like domain and active site of gelatinase B. J Biol Chem 275: 27964-27972, 2000.

17. Hu Z, Huo X, Lu D, et al: Functional polymorphisms of matrix metalloproteinase- 9 are associated with risk of occurrence and metastasis of lung cancer. Clin Cancer Res 11: 5433-5439, 2005.

18. Wright DK and Manos MM: Sample preparation from paraffinembedded tissues. In: PCR Protocols: A Guide to Methods and Applications. Innis M (ed). Academic Press, San Diego, pp153-158, 1990.

19. Tlsty TD: Cell-adhesion-dependent influences on genomic instability and carcinogenesis. Curr Opin Cell Biol 10: 647-653, 1998.

20. Zhu Y, Spitz MR, Lei L, Mills GB and Wu X: A single nucleotide polymorphism in the matrix metalloproteinase-1 promoter enhances lung cancer susceptibility. Cancer Res 61: 7825-7829, 2001.

21. Patterson BC and Sang QA: Angiostatin-converting enzyme activities of human matrilysin (MMP-7) and gelatinaseB/type IV collagenase (MMP-9). J Biol Chem 272: 28823-28825, 1997.

22. Ohbayashi H: Matrix metalloproteinases in lung diseases. Curr Protein Pept Sci 3: 409-421, 2002.

23. Lai HC, Chu CM, Lin YW, Chang CC, Nieh S, Yu MH and Chu TY: Matrix metalloproteinase 1 gene polymorphism as a prognostic predictor of invasive cervical cancer. Gynecol Oncol 96: 314-319, 2005.

24. Xu E, Lai M, Lv B, Xing X, Huang Q and Xia X: A single nucleotide polymorphism in the matrix metalloproteinase-2 promoter is associated with colorectal cancer. Biochem Biophys Res Commun 324: 999-1003, 2004.

25. Sfar S, Saad H, Mosbah F, Gabbouj S and Chouchane L: TSP1 and MMP9 genetic variants in sporadic prostate cancer. Cancer Genet Cytogenet 172: 38-44, 2007.

26. Clarizia AD, Bastos-Rodrigues L, Pena HB, Anacleto C, Rossi B, Soares FA, Lopes A, Rocha JC, Caballero O, Camargo A, Simpson AJ and Pena SD: Relationship of the methylenetetrahydrofolate reductase C677T polymorphism with microsatellite instability and promoter hypermethylation in sporadic colorectal cancer. Genet Mol Res 5: 315-322, 2007.

27. Ju W, Kim JW, Park NH, Song YS, Kim SC, Kang SB and Lee HP: Matrix metalloproteinase-1 promoter polymorphism and epithelial ovarian cancer: does ethnicity matter? J Obstet Gynaecol Res 33: 155-160, 2007. 